\title{
O traduzir-se de Kirinus: Textos bilíngues e literatura infantil
}

The Translation of Kirinus: Bilingual Texts and Children's Literature

\section{Daiane Lopes}

Universidade de Santa Cruz do Sul - UNISC - Rio Grande do Sul - Brasil

Resumo: Este artigo analisa a obra bilíngue da escritora Gloria Mercedes Valdívia de Kirinus, peruana radicada no Brasil, a partir dos textos destinados ao público infantil, escritos em português e em espanhol. Primeiramente, a autora é apresentada ao leitor: sua formação, sua produção literária e atuação profissional. No segundo item, aspectos de sua escrita bilíngue são explanados, sobretudo, hipóteses sobre o processo de produção dos livros são debatidas. Posteriormente, pressupostos teóricos sobre a tradução de textos para crianças são discutidos, visto que trarão subsídios para a análise das produções literárias escolhidas. Por fim, exemplos são retirados dos textos de Kirinus e analisados, consolidando a argumentação sobre a peculiar arte de produzir e de traduzir obras para a infância. Nesse sentido, este estudo considera o exercício da tradução de forma peculiar, visto que apresenta uma autora que cria e que, também, traduz o seu próprio texto, característica que facilita a construção de uma ideia de criança-leitora como um sujeito dotado de autonomia e de protagonismo na reelaboração dos dizeres de cada texto.

Palavras-chave: Autora-tradutora. Literatura Infantil. Texto bilíngue. Processo de tradução.

\begin{abstract}
Abstract: This article analyzes the bilingual work of writer Gloria Mercedes Valdívia de Kirinus, a Peruvian living in Brazil, based on medical texts for children, written in Portuguese and Spanish. First, the author is introduced to the reader: her background, her literary production and professional performance. In the second item, aspects of his bilingual writing are explained, above all, hypotheses about the book production process are discussed. Subsequently, theoretical assumptions about the translation of texts for children are discussed, as they will provide subsidies for the analysis of the chosen literary productions. Finally, examples are taken from the texts of Kirinus and Impulso, consolidating an argument about an art of producing and translating works for childhood. In this sense, this study considers the exercise of translation in a peculiar way, as it presents an author who creates and who also translates her own text, a characteristic that facilitates the construction of an idea of a child-reader as a subject endowed with autonomy and a leading role in the re-elaboration of the words of each text.
\end{abstract}

Keywords: Author-translator. Children's literature. Bilingual text. Translation process. 


\section{Conhecendo a Glória}

Gloria Mercedes Valdívia de Kirinus é peruana radicada no Brasil e, desde a década de 1970, reside na cidade de Curitiba, estado do Paraná. Formada em Turismo pela Escuela Nacional de Turismo de Lima Peru (1971), Kirinus aprofundou seu encantamento pelas palavras, especializando-se na área. Possui graduação em Letras/Português (1986) e em Letras Português/Espanhol pela Universidade Federal do Paraná (1991), instituição onde tornou-se, também, especialista em Literatura Brasileira (1987). Seu curso de Mestrado em Literatura Brasileira foi realizado na Pontifícia Universidade Católica do Rio de Janeiro (1991). Na Universidade de São Paulo, obteve o título de Doutora em Teoria da Literatura e Literatura Comparada (1998). Possui curso de pós-doutorado em Sociologia (Teorias do imaginário) com a tese "Tempo de Maradigmas" (2014), contando com a orientação do professor Michel Maffesoli, na Université Paris Descartes, Sorbonne.

Gloria Kirinus atuou como professora em várias instituições universitárias, como a PUCPR (Letras e Tradução Literária) e a Universidade Federal do Paraná (Teoria e Prática de Ensino). Autora de livros infantis e infantojuvenis, já publicou pelas editoras Paulinas, Paulus, Larousse, Melhoramentos e Cortez. Seus livros teóricos, Criança e poesia na pedagogia Freinet e Synthomas de poesia na infância foram publicados pela editora Paulinas. Participa com ensaios científicos, orelhas e comentários críticos em outras editoras universitárias, como Champagnat, Juruá, Vozes e Papirus.

Sua paixão pela palavra poética é expressa em obras direcionadas ao universo infantojuvenil, como conferencista em congressos nacionais e internacionais, como consultora na organização de feiras de livros e outros eventos culturais. A autora integra, ainda, núcleos de pesquisa e módulos de cursos de especialização, em diferentes universidades do Brasil. É membro curadora da Fundação Sidónio Muralha; integrante da Federação Internacional de Educadores Freinet - FIMEM, da Associação de Escritores e llustradores de Literatura
Infantil e Juvenil - AEI-LIJ e do conselho consultivo do site de leitura e literatura infantojuvenil "www.dobrasdaleitura.com". Atua como tradutora literária (português - espanhol - português) e foi votante do Prêmio da Fundação Nacional do Livro Infantil e Juvenil por mais de dez anos.

Kirinus já recebeu o título "Mérito da Educação" no estado do Amapá, "Bosque de Leitura" na cidade de Ponta Grossa, entre outras distinções. Uma das ações de que mais se orgulha, conforme constatamos em algumas entrevistas suas publicadas no meio digital, é a de ser criadora e ministrante do curso itinerante "Lavra-Palavra". Nessa oficina, a autora exprime sua paixão pelo poético na oralidade infantil.

O curso/oficina Lavra-Palavra é direcionado a docentes do Ensino Fundamental, a estudantes de Letras, Pedagogia, Biblioteconomia, Filosofia, Artes, entre outros integrantes. No site oficial da escritora, encontramos a informação de que poetas e escritores também participam. O principal objetivo do projeto é propiciar momentos de contato lúdico com a palavra e descobrir a dimensão poética da linguagem.

\subsection{Uma "palavreira" de nascimento}

Gloria Kirinus se diz "palavreira" de nascimento. Fascinada pela linguagem infantil, tenta dar conta do amor que sente pelas duas terras, o Peru e o Brasil, escrevendo livros bilíngues direcionados ao universo infantil/infantojuvenil. Segundo a escritora, esse amor continental, é o grande motivador de sua escrita enriquecida pelas culturas dos países vizinhos. Nesse sentido, se autodefine pelas seguintes características:

Sou peruana do Brasil, ou brasileira do Peru? Sou ambas as coisas, mas acima de tudo sou palavreira de nascimento. Fiz desta cisma de palavras o meu ofício itinerante. A minha linguagem nos entretantos do tempo permanece primordialmente analógica. Daí o meu fascínio pela linguagem infantil, pela linguagem popular, pela linguagem dos poetas. Quando menina, lá no Peru, ficava na ponta dos pés para espiar do outro lado das montanhas. Agora, morando deste lado da fronteira, tento espiar o que acontece nos países vizinhos. Para dar conta desse amor continental escrevo dobrado: de dia e de noite; em verso e em prosa; para adultos 
e para crianças; no quente e no frio... $E$ claro, em português e também em espanhol. (KIRINUS, 2014, http://www.gloriakirinus.com.br/index1.htm)

Essas são peculiaridades expressas nos paratextos de suas obras, demonstrando que a mescla de culturas é fonte de inspiração para a escrita de seus textos. Nesse sentido, torna-se impossível falar sobre a vida pessoal de Kirinus, sem falar da profissional: professora, escritora e pesquisadora. Parece que a realidade e a ficção se misturam na composição de seus livros, em que ela também revela um pouco do que é. Na entrevista que concede à revista Palavra Fiandeira, ela atribui outras características a si própria:

\begin{abstract}
Quem é Gloria Kirinus?
No espaço: um pouco peruana, um pouco brasileira.

No tempo: uma sexagenária distraída que perdeu de vista a folhinha que marca os anos.

$\mathrm{Na}$ vida: escritora, leitora, mulher, mãe, avó, filha, irmã, amiga.

No trabalho: formiga e cigarra inventando ofícios todo dia... com alguns títulos acadêmicos para avalizar as ousadias.

No planeta Terra: uma habitante a mais.

No céu astrológico: canceriana, com lua dupla e ascendente em aquário. (KIRINUS, 2009).
\end{abstract}

Gloria consegue "dizer-se" de maneira poética e, por isso, fazer a união dos fragmentos da vida na medida em que adere as habilidades de "escritora, leitora, mulher, mãe, avó, filha, irmã, amiga" aos aspectos mais relevantes de sua existência, ou seja, quando se autodescreve na vida.

Fala, também, do poder terapêutico que a escrita, a escuta e as leituras literárias possuem. Para ela, a poesia, além de ensinar a respirar melhor, auxilia o ser humano a viver melhor. Por isso, acredita que não há como separar a literatura em "para as crianças" ou "para os adultos". Afirma que a literatura é para o leitor que por ela se interessar. Assim, se determina como escritora e não como autora infantil:

Literatura Infantil é só para crianças?

É para todo leitor. Gosto de chamá-la de adulto-infanto-juvenil. Bartolomeu Campos Queirós faz uma pergunta bem oportuna, neste sentido: existe uma árvore para adulto e outra para criança? Respondendo esta pergunta digo que não existe nem árvore, nem lua, nem mar sujeito a compartimentos estanques. E nem existe livro para o dia do índio, dia do médico, dia do papel, dia da vacina, nada disso. Escrevemos para crianças e sabemos que os adultos selecionam os livros e temos esses leitores encantados com nossa literatura infantojuvenil. $\mathrm{E}$ a literatura infantojuvenil brasileira tem grande prestigio no exterior Já conferi isso em feiras de livros e encontros de literatura Internacional. O público não completa a visita se antes não passa no stand do Brasil. Só fico um pouco sem graça quando me chamam de autora infantil. É engraçado, vai ver que é por isso que nem notei que completei sessenta anos e completarei em breve vinte e cinco anos de autora. (KIRINUS, 2009, http://palavrafiandeira.blogspot.com.br/200 9/12/palavra-fiandeira-6.html).

No home de seu site, deixa uma mensagem de boas-vindas aos seus leitores. É como se o leitor estivesse sendo convidado a se encontrar com ela através de suas obras e da presença virtual desse contato lúdico entre autor, leitor e texto:

Seja bem-vindo ao meu site. Acomodei meus momentos e lugares de atuação, criação, inquietação, sobre esta tela que lembra o mar. E como o rio de Heráclito, tudo corre sempre novo surpreendendo o tempo. É indispensável sua leitura para que este encontro permita uma aproximação intensa e bela. (KIRINUS, 2014, http://www.gloriakirinus.com.br/index1.htm)

Essa acolhida se relaciona a um dos objetos de estudo da maradigma Gloria Kirinus. Em sua pesquisa de pós-doutorado, defende um paradigma que busque apoio no mar (seus movimentos, belezas e mistérios) para a compreensão e melhoria do mundo contemporâneo (BARROS, 2008).

Neste encontro virtual, o leitor poderá desfrutar de muitos encantos. Dentre eles, estão suas obras, que propõem o conhecimento não só estético, mas também cultural. Dona de uma extensa produção literária, a autora disponibiliza links de resenhas sobre seus textos e nos fala, resumidamente, sobre cada um deles. Ainda hoje, Kirinus mantém seu processo criativo em desenvolvimento, não só no que tange à escrita literária, mas em relação ao incentivo à leitura e à escrita criativa daqueles que trabalham com as palavras.

Como destaques de seu vasto acervo literário e pessoal, podemos citar, O sapato falador (1985). Se 
tivesse tempo (1988); O menino do mar (1990); Formigarra Cigamiga (1993); Sete quedas, sete anões e um dragão/ Siete cascadas, siete enanos y un dragón; $O$ galo cantou por engano/El gallo cantó equivocado; O camelo e o camelô e Tartalira, obra que foi indicada para participar da Feira do Livro de Frankfurt (todas de 1997); El niño e Quando as montanhas conversam/Cuando los cerros conversam (1998); versão bilíngue de Se tivesse tempo/ Si tuviera tempo (2000); Lâmpada de Lua/ Lámpara de Luna e Aranha Castanha e outras tramas (2002); Te conto que me contaram/Te cuento que me contaron (2004); Quando chove a cântaros/Cuando llueve a cántaros (2005). Seus textos teóricos de maior destaque são, como já afirmamos: Criança e poesia na pedagogia Freinet, publicado em 1998 e fruto de sua dissertação de Mestrado, e Synthomas de poesia na infância, de 2011 (ALEXANDRE, 2010).

Salientamos, assim, o papel de destaque que Gloria Kirinus desempenha enquanto representante da literatura paranaense e da literatura infantil brasileira.

\section{Os encantos de Kirinus em português e/y} español

Nascemos traduzíveis e prontos para fazer (p)arte do mundo inteiro. Gloria Kirinus

A adoção do português como língua literária por Gloria Kirinus foi, como ela explica, algo que aconteceu gradativamente: "A descoberta da literatura brasileira, juntamente com a descoberta da graça, do movimento, do ritmo, da força da língua do português do Brasil foi algo meio junto" (KIRINUS, 2011, http://midiaeducacao.com.br/?p=8414). Através do encantamento proporcionado pela literatura brasileira, passou a fazer uso de uma poética bilíngue, de modo que a língua espanhola, sua língua materna, também tivesse vez e espaço em consequência da mescla e da "irmandade" que possui com a língua portuguesa.

1 "Os prefixos ocorrentes em palavras portuguesas se originam do latim e do grego, línguas em que funcionavam como preposições ou advérbios, logo, como vocábulos autônomos." (Informação disponível
Gloria Kirinus experienciou, então, um processo de adaptação ao entrar em contato com uma outra cultura, que se mostra e se diz, também, através de uma outra língua. O Brasil, aos poucos, foi Ihe apresentando outras maneiras de enxergar e de dizer o mundo. O seu dizer poético, conforme apresenta em suas poesias, é pautado nisso: na oportunidade que the foi dada para fazer arte unindo duas culturas:

Passar da minha língua materna para o português do brasil foi algo muito interessante. acho que mereço contar um pouquinho aos ouvintes sobre isso. primeiro, me encantei com uma frase: "fazer arte". ouvia que as mães falavam: "onde estão as criança?; vai ver que estão fazendo arte; mas o fulano e a sicrana que estão demorando, ai, estão fazendo arte, com certeza." eu acho que essa expressão, "fazer arte", determinou que eu decidisse ficar no brasil: "mas é um país onde todo mundo faz arte, é aqui que eu quero morar, é aqui que eu quero ficar!" e algumas expressões muito interessantes, por exemplo, "cor de burro quando foge", eu acho isso bárbaro, bonito. né? a tal "dor de cotovelo"... agora, reencontrar essas expressões, na literatura, como outras, ainda, muito mais ricas na fala dos personagens, para mim foi uma espécie de passatempo precioso, de ir cuidando disso. eu acho que por ali eu começava a formar um certo rigor estético, uma linguagem rica em expressões do cotidiano, que ela já promete um imaginário, promete não, seduz o leitor ou o ouvinte para um universo fantástico, como acontecia comigo. eu ficava muito tempo querendo reconhecer, de fato, essa cor de burro quando foge. (KIRINUS, http://midiaeducacao.com.br/?p=8414).

Seu passatempo predileto, a busca por expressões metafóricas na literatura, conversa virtualmente com outros sujeitos que também aderem esse espaço de brincadeira, de ludismo sonoro que Kirinus expõe em seus textos. A expressão "fazer arte", em seu acervo pessoal, se baseia no sentido do prefixo "bi"1. Pelo fato de se inquietar com a criança, sua criação é pautada na coautoria, fazendo um chamamento para que esse tipo de leitor também

http://www.soportugues.com.br/secoes/morf/morf7. php). De acordo com a fonte referida, o prefixo "bi" tem origem latina e significa repetição; duas vezes. 
possa ser o criador. Além disso, o referido prefixo também se refere à presença de duas línguas e, por isso, de duas culturas que são colocadas em diálogo poético.

Não é possível saber, já que Kirinus não discorre sobre este aspecto em sua produção teórica e em suas entrevistas, a maneira como Kirinus compõem seus textos bilíngues. Será que eles são escritos, primeiramente, em português ou em espanhol? Para que língua ela faz a tradução de sua composição inicial? São mistérios que encantam e trazem a inovação literária.

Considerando a afirmação realizada por Kirinus de que sua língua literária é o português brasileiro, apostamos na hipótese de que a autora escreva seus textos, inicialmente, em língua portuguesa e depois os traduz para sua língua materna, a língua espanhola. Mas será que a inversão desse processo faria diferença no modo de produção de seus textos? De que forma ela manejaria as expressões que são típicas de um idioma para a passagem ao outro?

É interessante pensar nesse processo de criação, ainda mais, quando nos deparamos com textos destinados ao público infantil e infantojuvenil. A partir daí, já passamos a construir e a pensar sobre a maneira como Kirinus valoriza a criança e seus processos de interação na infância. A produção de seus textos já nos incita a ponderar que, para ela, a criança possui a habilidade para conhecer outros mundos. No caso específico de seus textos, à medida que apresenta ao leitor características da infância peruana, Kirinus conversa com suas memórias e com os aspectos que possibilitaram a ela o conhecimento da cultura brasileira.

Outro indício para isso, a tese de que Kirinus traduz os textos do português para o espanhol, é fato de que em seus livros o primeiro texto que é disposto na página sempre aparece em português, seguido de sua tradução para o espanhol. Isso acontece em todas as suas publicações, de acordo com o exemplo

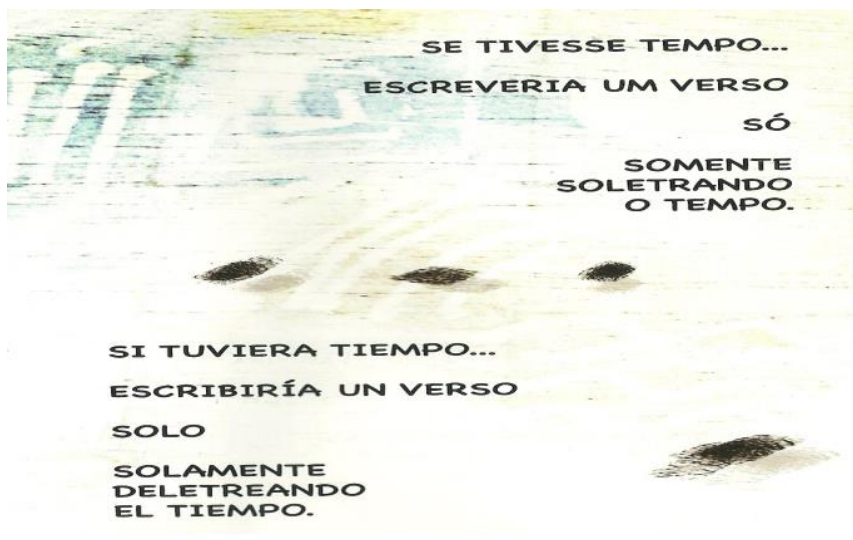

Figura 1: Exemplo da disposição física do texto bilíngue. Fonte: Se tivesse tempo I si tuviera tempo; texto de Gloria Kirinus

Mas esse não seria o enfoque definitivo para a argumentação, pois o fato de os livros serem publicados, primeiramente, no Brasil, já poderia desbancar nossa tese. Por isso, comentaremos essa hipótese, evidenciando o seu caráter de possibilidade.

A única obra em que temos a comprovação de que a tradução foi feita para o espanhol é o texto Se tivesse tempo / Si tuviera tiempo, do qual extraímos, inclusive, o exemplo acima. A referida produção foi publicada no ano de 1990 com o título monolíngue Se tivesse tempo. A versão bilíngue da obra é lançada somente no ano de 2000. Em função disso, temos mais um indício para apostar na tradução de sua língua literária para sua língua materna. As demais obras que serão citadas, aqui, foram publicadas em escrita bilíngue.

\subsection{Kirinus enquanto autora-tradutora}

Primeiramente, precisamos justificar a escolha, neste estudo, do uso do verbo "traduzir" ao invés de "verter". Sabemos que eles podem ser utilizados como sinônimos na medida em que expressam a ideia de transferência, não só de uma palavra para outra, mas dos significados que nelas estão contidos. Entretanto, de acordo com Amorim (2010), os tradutores profissionais, estabelecem uma diferença entre eles. Nesse sentido, o termo tradução se refere à passagem de um texto em língua estrangeira para língua nativa. O vocábulo versão exprime o contrário: passar um texto da língua nativa para a língua estrangeira. 
Outra diferença que estabelecem, conforme Amorim, se concentra no fato de que, no senso comum, a palavra versão tem sentido mais voltado para a subjetividade e se refere à determinada interpretação para o texto-base. Em contrapartida, a tradução exige um sentido objetivo e não permite determinadas adaptações do texto-primeiro.

Considerando esses dois fatores, o uso, neste texto, da expressão autora-tradutora, para o processo que Gloria Kirinus realiza, se atrela à fidelidade de sentidos que seus textos possuem nas duas línguas. Se apostamos na hipótese de que seus textos são traduzidos do português, sua segunda língua, para o espanhol, sua língua materna, o termo tradução, de acordo com o conceito apresentado, se adéqua de maneira mais convincente ao nosso propósito.

É interessante atentarmos para a questão de que Kirinus, no sentido que estamos atribuindo para o seu processo criativo, também realiza a tradução da infância peruana. Se o texto é escrito, primeiramente, em português, como confiamos, ela pensa a sua cultura de pertencimento em outra língua - que na verdade é sua segunda língua - e depois a traduz para o seu contexto de origem, que é a língua espanhola. Nesse sentido, é como se houvesse uma inversão no processo de contar. Aquilo que deveria ser pensado, inicialmente, em espanhol, é escrito em português, demonstrando que sua capacidade criadora está para além das línguas, está na expressão do multiculturalismo da América Latina.

Da mesma forma, acontece com as características da cultura brasileira. Mas, nesse caso, o diferencial é que ela é pensada em português, primeiramente, e transferida para o espanhol em um segundo momento. Nesse sentido, o processo de tradução da infância brasileira para o espanhol não seria tão complexo como o descrito no parágrafo anterior.

Gloria Kirinus, então, age poeticamente. Ao escrever de forma bilíngue ela precisa tomar decisões, que vão desde a opção do uso de um vocábulo ao

2 "O fazer, o poïen, do qual desejo me ocupar, é aquele que termina em alguma obra e que eu acabarei restringindo, em breve, a esse gênero de obras que se convencionou chamar de obras do espírito. São aquelas invés de outro até a atribuição de sentidos para os acontecimentos fantásticos de seus textos. Tais decisões são tomadas levando em consideração a ideia de criança que possui e que explicita em seus textos, que somente pelo fato de estar em contato com duas línguas ao mesmo tempo, já aponta para uma criança capaz e protagonista do ato da leitura ou da escuta.

Kirinus ressalta, na citação já mencionada, que, aos poucos, foi ganhando certo rigor estético em relação à língua portuguesa. Interpretamos essa passagem em função da atribuição de significados para a forma como percebeu os textos literários em português, o que, com certeza, influenciou em sua própria produção. O rigor, na verdade, é aquilo que existia dentro dela, essa predisposição para a imersão em uma outra cultura, levando em consideração a sua bagagem cultural e as suas reservas de entusiasmos pelo conhecimento, literário e cultural. Sua poética não é uma poética pela norma, mas sim, a que está atrelada ao ato de vislumbrar a linguagem portadora do poïen², em suas mais diversas formas de manifestação, como algo que é próprio do sujeito que faz.

Na medida em que escreve sobre seu povo, ela nos conta sobre as memórias que o Peru carrega e as coloca em diálogo com as do Brasil. Portanto, a escrita bilíngue favorece ainda mais o diálogo entre aquilo que Kirinus já conhecia e aquilo que passou a ter contato quando escolheu viver no Brasil. $O$ bilinguismo é a comprovação, então, dessa herança linguística e cultural. Herança brasileira ou peruana?

No paratexto da obra Se tivesse tempo/Si tuviera tiempo, Kirinus comenta sobre o encontro que teve com Ferreira Gullar em um seminário da PUC-RJ, em que expôs ao poeta a sua angústia ao olhar para a sua língua materna e, por vezes, sentir-se sem identidade linguística. Declara, então, a resposta recebida:

Ele ouviu com essa capacidade de ouvir que têm os poetas. E respondeu:

que o espírito quer fazer para seu próprio uso, empregando para esse fim todos os meios físicos que possam Ihe servir". (VALĖRY, 1999, p. 180-181). 
- Aproveite toda a força do espanhol e dos poetas peruanos a favor de sua escrita em português.

- E se sai algo híbrido?

- Melhor ainda... (KIRINUS,

2010, contracapa).

A autora afirma, então, que foi a partir daí que ela sentiu a necessidade de traduzir traduzindo-se. Notamos, dessa forma, que também se autoconceitua como autora-tradutora, acreditando em sua arte. Deseja que suas obras possam representar a expressão de um continente bilíngue, que é a América Latina:

Gostaria que essa experiência de sentir um pouco de mim em todo mundo se repetisse nos brasileiros que me possam ler também em espanhol. E que o contrário também aconteça, fraternizados por esta América que nos congrega em continente bilíngue. Cada vez os povos estão mais próximos e cada vez mais nossa leitura ganha 0 dinamismo do encontro dos mares, da conversa entre montanhas e de colóquio de nuvens. Tudo isso a poesia de todos os povos faz há muito tempo, é a criança querendo saber como é seu nome em outra língua. Nascemos traduzíveis e prontos para fazer ( $p$ )arte do mundo inteiro. (KIRINUS, 2010, contracapa).

A principal inovação em Kirinus está no fato de ser uma autora que se traduz a si própria. Ao passo em que transfere o seu texto de uma língua para outra, ela também discorre sobre a identidade do povo latinoamericano. Do mesmo modo, toma conhecimento de si ao provocar a mudança no leitor, que também principia um processo de descoberta sobre sua própria identidade.

\section{Processo de tradução}

Ainda não desfrutamos de muitos estudos sobre a escrita bilíngue em obras infantis. Devido a isso, nossos pressupostos teóricos terão como base maior o processo de tradução, que também é parte, conforme salientamos, da escrita de Kirinus. A estudiosa Thais Verdolini realiza pesquisas referentes à tradução de obras infantis no Brasil. Nessa perspectiva, ela salienta inúmeros fatores que apontam para o descaso referente à qualidade nesse tipo de trabalho:
Nesse contexto em que a tradução é atividade essencial e no qual os estudos tradutórios se voltam para os mais variados setores do conhecimento - como as dificuldades de se traduzir um poema, os aspectos psicanalíticos da tradução e a visibilidade do tradutor, entre outros - um campo ainda a explorar é o que descreve e analisa a tradução de obras para os públicos infantil e juvenil. Não há registros de pesquisa sobre esse tema específico no Brasil. (VERDOLINI, 2012, p.2).

Nesse sentido, a autora explana que a pressa do mundo contemporâneo chegou, também, ao mercado editorial, principalmente no que tange aos processos de tradução. Porém, ressalta que os mecanismos relativos a esse trabalho não têm recebido a atenção que merecem e cita alguns fatores que comprovam sua argumentação: a própria velocidade da informação, a má remuneração dos profissionais tradutores e, em relação especificamente à literatura infantil, o fato de ainda ser considerada como um gênero "menor":

Traduzir para crianças pode parecer, nesse mercado, uma fatia lucrativa e de fácil trato, baseando-se na pseudo-simplicidade da tarefa de verter literatura infantojuvenil. Para a grande maioria das editoras, um gênero ingênuo, que pode contar com tradutores menos experientes. Entretanto, é preciso saber muito mais do que dois idiomas para realizá-la. (VERDOLINI, 2012, p. 5).

Esse saber além dos idiomas está, sobretudo, no conhecimento do conceito contemporâneo de infância, que também é volátil. É preciso que o tradutor conheça sobre o universo infantil e que saiba o que é adequado ou não para as experiências das crianças leitoras. Através do conhecimento de uma outra cultura, exposta pela tradução, se o tradutor ter o cuidado de não infantilizar o texto, por exemplo, a curiosidade pode ser a principal arma propulsora de um adulto leitor.

A autora cita o relevante papel que teve Monteiro Lobato no trabalho relativo à tradução de obras para o público infantojuvenil brasileiro. Para ela, Lobato tentou aprimorar, ao seu estilo, algumas traduções nebulosas que foram dirigidas às crianças. Entretanto

a visão a respeito das crianças foi se modificando com o passar das décadas, mas parece que a seriedade da tradução para elas não seguiu, necessariamente, o 
mesmo rumo. Traduções imperfeitas e provável indiligência das editoras quanto à seleção de tradutores e/ou à revisão das obras traduzidas publicadas mostraram-se frequentes na pesquisa que realizamos. (VERDOLINI, 2012, p. 14).

A pesquisadora salienta que a tradução de um texto infantil deve ser fruto de pesquisas sobre o todo da obra. Além disso, a identificação do tradutor com a produção e sua linguagem é requisito essencial para a fluência no texto da língua de chegada. Afinal, "uma melhor compreensão sobre termos culturais, gíria, oralidade e variantes linguísticas certamente contribuiriam para traduções mais fluentes e fiéis ao tom do texto original" (VERDOLINI, 2012, p. 14).

A tradução, então, não pode ser considerada uma tarefa fácil. Como vimos, não são apenas a(s) língua(s) que estão envolvidas nesse processo. A cultura, o contexto e o público-alvo são, também, fatores que influenciam nesse trabalho. "A literatura infantojuvenil está inserida em um sistema cultural como qualquer outro tipo de literatura e o tradutor que se dedica a ela deve conhecer com maestria o gênero, seus leitores, sua linguagem, suas idiossincrasias" (VERDOLINI, 2012, p.14).

Renata Mundt (2008), pesquisadora e também tradutora, propõe a reflexão sobre outra questão referente ao assunto: as rígidas fronteiras entre tradução e adaptação. Salienta, assim como Verdolini, que o processo de tradução é influenciado por diferentes instâncias: a visão de criança, a cultura de partida e também os interesses de diversos agentes envolvidos, como é o caso do próprio tradutor, dos editores, dos revisores, ilustradores, educadores, pais, professores e os próprios leitores. De uma forma ou de outra, esses participantes influenciarão no processo de tradução de um texto destinado ao público infantojuvenil. Os dois aspectos mais relevantes são a consideração que deve ser dada à visão de criança e à cultura de partida do texto.

Para Mundt (2008, p. 1), a adaptação é vista como um processo típico da atividade de tradução, definido por ela como "aquele em que a opção pela literalidade na tradução cede lugar a uma interferência e a uma alteração mais profundas". A adaptação é realizada, então, devido ao surgimento, no texto original, de alguns elementos "intraduzíveis" de forma literal. Nesse sentido, a autora cita algumas possibilidades para isso:

Alguns exemplos de elementos que podem exigir a adaptação por parte do tradutor são dados específicos de uma cultura (como nomes, títulos, comidas, costumes e hábitos, jogos, versos, mitologia e folclore, referências históricas e literárias). Além disso, podem exigir adaptação: título, aspectos estilísticos, ritmo, estilo e comprimento da frase, dialetos, socioletos e linguagem corrente, jogos de palavras. Algumas formas de adaptação possíveis são: quando se trata apenas de um termo ou expressão, a utilização do termo acrescentando uma explicação no próprio texto; a substituição do termo/ expressão por um conteúdo explicativo (tradução explicativa); a omissão do termo/ expressão, o que pode ser problemático e obrigar à reformulação do conteúdo no qual ele está contido; a utilização de uma explicação externa ao texto; o uso de um termo equivalente; o uso de um termo semelhante; a simplificação, ou seja, o uso de um conceito mais geral no lugar de um específico; a localização ou domesticação, processo em que todo o conteúdo é aproximado do ambiente cultural do leitor da tradução. Quanto a esse último método, ele implica em um conceito mais geral, que inclui a postura geral do tradutor e/ou de outras instâncias frente à tradução. Ele pode optar por domesticá-la ou estrangeirizá-la. (MUNDT, 2008, p. 2).

Os aspectos citados fazem parte das possibilidades de escolhas por parte do tradutor, que também desempenha, nesse caso, um papel de coautoria. Entretanto, apesar das possíveis variações que podem existir durante o processo, deve ter, como principal princípio, "a manutenção de um aspecto essencial do original: o seu conteúdo, o seu aspecto lúdico, informativo, ancoragem em elementos conhecidos etc" (MUNDT, 2008, p. 2-3).

No mesmo sentido, a autora comenta que a fidelidade ao texto original é presença constante em um trabalho de tradução que tenha respeito pelo texto, o que não pode ser confundido com literaridade, fidelidade à letra. No caso da literatura destinada ao público infantil ou juvenil, outro aspecto que se sobressai é a questão da faixa etária do leitor, que também precisa ser considerada. Para a estudiosa, uma boa tradução é aquela que foge da "adaptação manipuladora", ou seja, aquela que descola o sentido 
do texto primeiro e não obedece aos princípios básicos desse trabalho, já citados anteriormente.

Mundt (2008) cita, então, algumas características que são específicas da tradução no âmbito da literatura infantojuvenil. A sua pesquisa é pautada na maneira como conceitua essa literatura "aquela que foi escrita, publicada para e/ou lida por crianças e jovens" (p. 3) -, bem como em livros que já estão no mercado, catalogados como literatura infantojuvenil. A primeira característica que discute é em relação ao público. Para a tradução, é essencial que o profissional conheça as peculiaridades do leitor:

seu nível de desenvolvimento cognitivo, sua bagagem cultural, suas características dentro de sua cultura e a visão que a própria cultura e sociedade nela inserida têm dessa criança (no caso do tradutor, é preciso conhecer a visão das duas culturas). (MUNDT, 2008, p. 3).

Daí decorre a responsabilidade dessa atividade. Muito mais do que ter domínio de ambos os idiomas, o tradutor é o encarregado pela forma como uma outra cultura será apresentada ao leitor infantil. Os aspectos culturais, que para a criança não desconhecidos, passarão a fazer parte de sua bagagem de conceitos sobre o mundo e travarão um diálogo com sua cultura de pertencimento.

Outra função do tradutor infantojuvenil é a de manter a ludicidade contida na produção original. Para tanto, se utiliza de seu potencial criativo e aceita o desafio de manter a brincadeira proposta pelo autor e de aproximar a criança das diferenças culturais, as quais, por meio do seu trabalho, o leitor será exposto.

A segunda característica citada pela autora é referente à assimetria. $\mathrm{O}$ tradutor negocia com todos os adultos participantes da produção da obra - o autor, o editor, o revisor - as suas visões de crianças, as quais, obviamente, não serão as mesmas. Sem falar, ainda, que os livros são comprados para as crianças também por adultos. Isso quer dizer que, para chegar até as mãos do leitor, o livro passa por esse último filtro, que culminará, também, na escolha da melhor concepção de criança na visão de um adulto. Isso porque "a tradução também inclui a imagem que o tradutor adulto tem da criança, de sua cultura e da cultura de partida, pois esta vai influenciar várias de suas decisões tradutológicas" (MUNDT, 2008, p. 4).

A terceira característica diz respeito à função, que possui um diferencial na literatura infantojuvenil. Além de entreter e provocar prazer estético, a literatura para a criança tem a função de apresentar-lhe outra cultura. No caso da tradução, a responsabilidade é ainda maior, pois a criança é exposta a um conhecimento bastante distinto da ambientação em que convive. Lembremos que, para tanto, o elemento lúdico é constante. Daí que surge a necessidade de adaptação de alguns dados culturais muito específicos. Nesse caso, se enquadram os simbolismos e as construções metafóricas, já que uma tradução literal, na maioria dos casos, não é suficiente para dar conta do verdadeiro sentido.

A quarta e última característica exposta pela autora é relativa à ilustração. Sabemos da importância das ilustrações em uma obra infantojuvenil, já que não serve apenas como enfeite, mas é parte integrante da obra e complementa o processo de compreensão. Por isso, a ilustração é considerada, também, pelo tradutor. Algumas alterações referentes à tradução podem entrar em conflito com a ilustração original. Outro caso ocorre quando a ilustração acarreta mudanças na maneira de traduzir o texto.

Finalizando a exposição de seu estudo, a autora ressalta a relevância do processo tradutológico na literatura infantojuvenil. Alerta que, em muitos casos, as distorções resultam na manipulação dos conteúdos dos textos. Isso acontece quando a criança é vista com uma visão equivocada, ou seja, é considerada como um "sujeito menos sabedor". Da mesma forma, a literatura a ela oferecida é vista com um "valor menor", o que resulta na falta de cuidados relativos à tradução, que vão desde a escolha do tradutor até as concepções que este possui sobre a infância e a criança.

Argumenta, por esses motivos, que a tradução para o público infantil engloba, necessariamente, o conceito de adaptação, levando em consideração o respeito e a fidelidade ao texto original e a concepção de criança enquanto sujeito protagonista de suas ações: 
Devido ao perfil de seu público que torna o lúdico, as brincadeiras, os jogos e as referências a dados culturais quase sempre presentes na LIJ, o conceito de tradução para a criança e o jovem engloba necessariamente a adaptação. Além disso, esse mesmo público muda a relação das instâncias interferentes com a obra e acrescenta novas, inexistentes no caso da literatura publicada para adultos, por exemplo. (MUNDT, 2008, p. 8).

Considerando a escrita de Kirinus como um processo de tradução do seu próprio texto, podemos expor alguns comentários alusivos aos estudos realizados por Verdolini e Mundt e que nos aclararam sobre alguns aspectos presentes na composição poética de Kirinus. Nesse sentido, não precisaremos levar em consideração o fato de Kirinus compor o seu texto original primeiramente em português ou em espanhol. Discorreremos sobre o processo que realiza ao passar o seu texto para a outra língua e ao apresentar ou contrapor culturas.

\subsection{Nos textos de Kirinus...}

Comprovando as afirmações realizadas no item anterior, demonstraremos alguns exemplos extraídos das obras de Gloria Kirinus. Isso porque a inovação nelas exposta, diz respeito, também, a essa maneira de escrita que foge da tradicional: são duas línguas e, por isso, duas culturas apresentadas à criança. Não serão expostas, aqui, todas as possibilidades. Selecionamos alguns exemplos em que as adaptações relativas à hipótese de tradução do português para o espanhol ficam mais evidenciadas.

A escrita dupla de Kirinus é facilitada devido ao forte vínculo criado pela autora com a cultura brasileira. Um dos requisitos essenciais para o tradutor é o conhecimento aprofundado da cultura de partida. Levando em consideração o fato de a escrita de Kirinus partir da língua portuguesa, podemos afirmar que antes do início de sua produção literária, a autora passou por um processo de adaptação à cultura brasileira e, em consequência, à língua portuguesa.

A partir desta aproximação com a cultura do Brasil, o processo inverso que apostamos que realize na tradução das obras, ao traduzir os textos para sua língua materna, é facilitado. Outro aspecto que contribui para sua escrita bilíngue são as proximidades existentes entre a língua portuguesa e a língua espanhola. Para Rodríguez (2011, http://www.filologia.org.br/viisenefil/01.htm),

o espanhol e o português são duas línguas românicas que têm muito em comum, além de sua proximidade geográfica e de sua origem. O espanhol é, com exceção do galego, que teve origem comum com 0 português, a língua que tem mais afinidade com o português.

O estudioso comenta, também, que, na sua grande maioria, as fontes do léxico do espanhol são as mesmas do português. No entanto, os fatores que contribuíram para a existência de um grande número de termos diferentes, assim como a presença de outros tantos semelhantes na forma, mas diferentes no significado, foram a seleção do vocabulário e a evolução semântica de ambas as línguas. Apesar de reforçar a ideia de serem as duas línguas mais semelhantes,

Rodríguez

(2011, http://www.filologia.org.br/viisenefil/01.htm) alerta que:
o espanhol e o português, embora tendo como tronco comum o latim ibérico, apresentam diferenças em todos os seus aspectos, desde os fonético-fonológicos até os lexicais, sem deixar de lado algumas diferenças morfológicas e sintáticas. Não há dúvida de que para uma simples compreensão, principalmente da língua escrita, a semelhança pode ajudar, porém, para efeito de aprendizagem como segunda língua, a facilidade pode ser mais aparente que real.

Kirinus possui o domínio de ambas e, por isso, se sente à vontade em sua escrita dupla. É por isso que consegue pensar a infância de sua cultura de pertencimento, a peruana, em português e traduzi-la para o espanhol. De forma similar, porque é pensada em português, a infância brasileira é traduzida para sua língua materna.

Nos textos de Kirinus, a questão do descaso comum, como apontamos, na tradução para o público infantojuvenil, não ocorre devido ao fato óbvio de ela ser a autora de ambos os textos. Nesse caso, o tradutor não é o coautor é o próprio autor. As mesmas concepções de crianças são expressas no texto primeiro e no traduzido. Por isso, a editora não precisa 
ter a preocupação de selecionar tradutores para a edição bilíngue que será publicada, pois a obra é completada com as singularidades da autoratradutora.

Gloria conhece as peculiaridades de seu leitor, tanto aqueles que possuem domínio da língua espanhola quanto aqueles que dominam a língua portuguesa, assim como os que são bilíngues. Seus leitores também podem fazer escolhas, as quais, dentre tantas, se referem à possibilidade de leitura em uma ou na outra língua, ou em ambas. Mas mesmo optando pela leitura apenas em português ou somente em espanhol, a criança está em contato com outra cultura, devido às temáticas apresentadas nos textos.

Isso porque Kirinus possui relações próximas com as duas culturas. Conhece a cultura de partida, que abriga a língua portuguesa, através de seus estudos e vivências enquanto cidadã paranaense. Reconhece-se na cultura de chegada de seu texto, a que abriga a língua espanhola, pelo fato de ter nascido no Peru e de lá ter vivenciado uma boa parcela de sua experiência de vida, sobretudo, sua infância. Dessa maneira, ela cumpre uma das funções da literatura infantojuvenil, senão a principal, de apresentar outra cultura ao leitor. Kirinus vai além: apresenta duas (ou até mais, pois em algumas passagens de seus textos faz alusões a outros países latino-americanos).

Em função de Gloria Kirinus ser a tradutora de seus próprios textos, o nível de assimetria, elemento constante nas obras destinadas ao público infantil, é diminuído. Ela não precisa travar um diálogo com o tradutor da obra na tentativa de não modificar a visão de criança e de infância que expressa. A conversação acontece consigo mesma. Por ser a autora, enquanto tradutora se mantém fiel ao texto-primeiro.

A exposição dos aspectos comentados comprova que a aproximação entre o texto em português e o que supomos ter sido a tradução para o espanhol é bastante perceptível em suas obras. A proximidade de ambas as línguas e o fato de ela ser a tradutora de seus próprios textos são os principais

${ }^{3}$ Citaremos sempre o conjunto de duas páginas devido ao fato de abrigarem o mesmo texto, a primeira em português e a outra em espanhol. fatores que contribuem para que os índices de adaptações nas traduções sejam baixos e perceptíveis, acreditamos, somente para os leitores analíticos. Vejamos alguns exemplos.

Kirinus, com exceção de pouquíssimos casos, consegue manter o sentido do texto original, seu conteúdo e seu ludismo. As principais mudanças que ocorrem são referentes às expressões específicas de determinada língua. Citamos o exemplo da página 4$5^{3}$ da obra Quando as montanhas conversam/Cuando los cerros conversan. A expressão de 'mãos dadas' no português não possui a tradução literal para o espanhol. Kirinus, como boa conhecedora do idioma, a substitui pela expressão 'de la mano'. Esse seria um dos casos em que, embora de forma sutil, Kirinus faz uso da troca da literaridade pela adaptação, ao se deparar com a expressão intraduzível de forma literal.

O mesmo ocorre na página 8-9 da referida obra, em que a palavra 'micagens', intraduzível para o espanhol, é substituída pela expressão 'mil muecas'. $\mathrm{O}$ (s) sentido(s) que a autora atribui para os termos é de trejeitos estranhos, no caso da obra, praticados pelas montanhas quando imitam os humanos. Podemos comentar, além disso, a forma como algumas brincadeiras infantis são nomeadas no Brasil, diferindo da maneira como são chamadas nos países hispanofalantes. Exemplificamos com o uso da expressão 'a las escondidas' para a tradução da brincadeira 'esconde-esconde"4.

A adaptação relativa aos gêneros das palavras também ocorre durante a transferência de uma língua para a outra. A tradução que Kirinus atribui para o vocábulo 'montanhas' é a de 'cerros', ou seja, há a passagem do gênero feminino para o masculino. Isso influenciará na atribuição de outras características relativas a eles, pois na página 28-29, enquanto as 'montanhas' são descritas como 'belas que adormecem', os 'cerros' são os 'bellos durmientes'.

A cultura apresentada nesse texto é, de maneira mais evidente, a peruana. O próprio título faz alusão às montanhas, o que nos deixa implícito a

4 O exemplo pode ser encontrado na página 12-13 da obra Quando as montanhas conversam/Cuando los cerros conversan, de Kirinus. 
presença da Cordilheira dos Andes. Entretanto, Kirinus entrelaça as culturas ao dar vida às montanhas e ao apresentá-las considerando todo o potencial criativo que a criança possui, fazendo referências a muitas brincadeiras praticadas na infância brasileira também.

Da mesma forma, as ilustrações, de responsabilidade de Graça Lima, são condizentes com a arte peruana e não entram em conflito com os textos. Uma mesma ilustração serve para o texto em espanhol e em português, uma vez que é apresentada no centro das duas páginas, conforme este exemplo: obra Quando chove a cântaros/Cuando llueve a cántaros).

A própria ilustradora menciona o fato de Gloria Kirinus reconstruir, de maneira poética, alguns lugares da América Latina, comprovando a apresentação de outras culturas ao leitor-criança. O texto Quando chove a cântaros/Cuando llueve a cántaros inicia com um questionamento: "É verdade que em Lima não chove?" (KIRINUS, 2012, p. 4). A partir dele, a autora principia a descrição de uma série de acontecimentos, fantásticos e reais, ocasionados pela chuva. Dentre eles, a enchente, que de maneira implícita, a autora
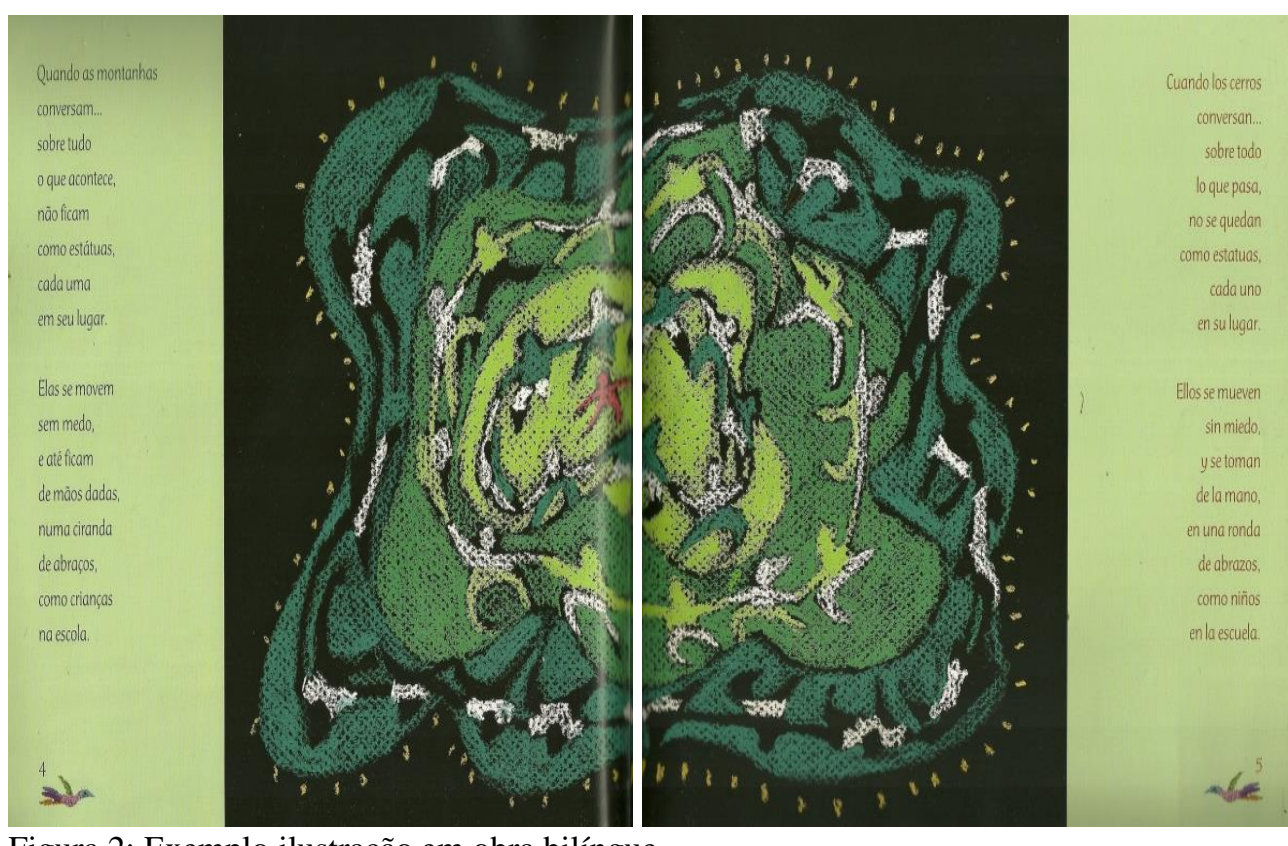

Figura 2: Exemplo ilustração em obra bilíngue.

Fonte: Quando as montanhas conversam/ Cuando los cerros conversam; texto de Gloria Kirinus

elucida como um acontecimento relativo ao Brasil.

Nesta obra, o leitor, sobretudo aquele que possui certo domínio de ambas as línguas, pode perceber, na página 10-11, o uso que a autora realiza dos falsos cognatos. A palavra que exemplifica a questão é 'copos'. Na língua espanhola, 0 termo correspondente é 'vasos', que, no português, possui um sentido diferente. Aqui, percebe-se a inserção de palavras que podem ser escritas de maneira igual ou semelhante, mas que possuem significados distintos, exigindo

Outro livro de Gloria Kirinus ilustrado por Graça Lima é intitulado Quando chove a cântaros/Cuando llueve a cántaros. Nele é realizado o mesmo estilo de ilustração do anterior, ou seja, as imagens são dispostas entre os dois textos. Lima também se sente coautora da obra de Kirinus e diz o seguinte sobre seu trabalho:

Sou ilustradora há muito tempo. Aliás, desde pequenininha, pois a ilustração é uma história contada com imagens, e eu contava minhas histórias por todo o espaço rabiscável onde passava. Fiz o Quando chove a cântaros e um outro livro da Glória Kirinus que também falava de lugares poéticos da América Latina. Adoro a ideia de estar entrelaçada com a cultura dos povos vizinhos. (LIMA, 2012, contracapa da um leitor mais atento e experiente para a percepção dessa possibilidade de manusear e de, por isso, brincar com a língua.

A religiosidade tanto do povo peruano quanto do brasileiro é expressa no texto. Como a maioria da população dos dois países se declara católica, Kirinus não enfrenta problemas na tradução de nomes de figuras que representam as crenças da(s) população(ões). São Pedro/San Pedro, por exemplo, é mencionado, enquadrando-se também nas atribuições que o senso comum faz ao santo em relação à temática da própria obra.

A proximidade das línguas também facilita a exposição de expressões idiomáticas. É o caso da 
frase 'Que mil raios me partam!', escrita na página 1516. Ao ser transferida para a língua espanhola, não evidenciamos grandes mudanças 'iiiQue mil rayos me partan!!!'.

Um tradutor pode se deparar com uma palavra ou uma expressão inexistente em outra língua? Sim, é - caso da palavra saudade, escrita por Kirinus na página 4-5 da obra Te conto que me contaram/Te cuento que me contaron. Vejamos como Kirinus consegue aproximar seus dizeres poéticos:

Te cuento que me contaron

que los cuentos andan sueltos.

Salieron de no sé dónde

cargaditos de recuerdos. (KIRINUS, 2004, p. 4-5).

Te conto que me contaron

que os contos andam soltos.

Saíram de não sei onde

com saudade a tiracolo.

No texto, a expressão 'saudade a tiracolo' é substituída por 'cargaditos de recuerdos'. A tradução literal desta última expressão é "carregadinhos de recordações", o que não comprova uma correspondência exata com a primeira. No entanto, no sentido poético do texto, esta foi a melhor maneira que Kirinus encontrou para representar os dois versos em ambas as línguas. Primeiramente, porque saudade é uma expressão típica da língua portuguesa. Em segundo lugar, porque a expressão 'a tiracolo' também não possui uma tradução específica para a língua espanhola, sendo que a que mais se aproximaria seria 'en bandanas'. De certa forma, está justificada a aproximação de sentidos, uma vez que saudade pode, também, ser oriunda de recordações.

Consideramos a escrita poética de Kirinus inovadora devido ao fato de se constituir por normas próprias, não pautadas nas regras da teoria literária, mas no compromisso e na proximidade com a oralidade. Todavia, a título de verificar a adaptação

\footnotetext{
${ }^{5}$ As citações não obedecem ao espaçamento entre linhas e ao tamanho de fonte normatizados pela ABNT para que o leitor possa melhor visualizar a escansão do texto. A configuração do poema se refere às sílabas métricas, alternadas entre as cores azul e preto. As sílabas destacadas com letras em caixa alta representam o esquema rítmico dos versos.

${ }^{6}$ Preferimos utilizar esta terminologia, texto-base, ao invés, por exemplo, da expressão texto original. Isso porque a construção
}

métrica da tradução, percebemos que, em alguns casos, ela é mantida, conforme o exemplo ${ }^{5}$ extraído da obra mencionada:

\begin{tabular}{|c|c|}
\hline 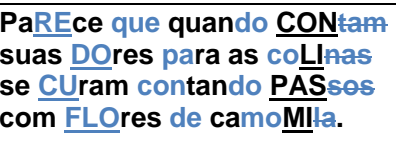 & $\begin{array}{l}\text { PaREce que cuando CUENtan } \\
\text { sus MAles a las coLlyas } \\
\text { se CUran contando PAsos } \\
\text { con FLOres de manzaNIIHa. } \\
\text { (KIRINUS, 2008, p.22-23). }\end{array}$ \\
\hline
\end{tabular}

No exemplo, percebemos a composição dos versos em redondilha maior, com acentos na segunda e na última sílaba métrica. Tanto em espanhol quanto em português o texto obedece à mesma escansão e ao mesmo esquema rítmico. Atentamos para o fato de que isso é resultado de uma escolha realizada pela tradutora. No segundo verso do poema, aparece a palavra 'dores'. A tradução literal para o espanhol seria 'dolores'. No entanto, tal eleição quebraria o ritmo colocado no texto, resultando na adaptação da palavra para "males", que também possui duas sílabas métricas, sendo a primeira tônica.

Mas nem sempre esse tipo de adaptação é possível no momento da tradução. Este exemplo comprova a impossibilidade de sempre se adequar o esquema rítmico, oriundo da sintaxe e dos vocábulos específicos de cada língua, no momento da tradução. A adequação rítmica poderia ocasionar a falta de fidelidade ao texto-base ${ }^{6}$ :

\begin{tabular}{|c|c|}
\hline 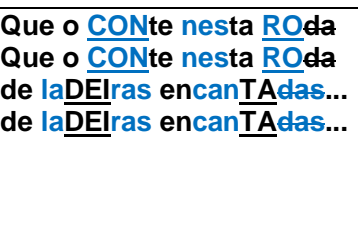 & $\begin{array}{l}\text { Que lo CUENte en esta } \\
\text { RONda } \\
\text { Que lo CUENte en esta } \\
\text { RONda } \\
\text { de laDEras encanTAdas... } \\
\text { de laDEras encanTAdas... } \\
\text { (KIRINUS, 2008, p.26-27). }\end{array}$ \\
\hline
\end{tabular}

Como percebemos, o primeiro poema, em português, é composto por dois versos considerados hexassílabos, com tonicidade na segunda e na última sílaba métrica, e por outros dois versos correspondentes à redondilha maior, com acentuação na terceira e na última sílaba. O segundo poema, ou

bilíngue da escritora, pela percepção dos trechos já comentados, parece ocorrer de forma concomitante. Na medida em que a escritora produz o texto, vai pensando na sua versão para a outra língua. Essa seria, aos nossos olhos, a sua maneira de poetizar a tradução, na tentativa de traduzir aquilo que quer dizer não só pelo sentido literal, mas levando em consideração o aspecto estético da obra. 
seja, a tradução para o espanhol, é formado por quatro versos, todos equivalentes à redondilha maior, acentuados na terceira e na última sílaba poética.

No texto Tartalira/Tortulira, temos outro exemplo de substituição de expressão não existente na língua de chegada, trata-se do termo 'de fora' da língua portuguesa. No início do enredo poético, estão os seguintes versos, que também nos contam uma narrativa. Na realidade, é uma história, a da Tartalira, que é escrita em versos, ou seja, tem a forma de poema e tom narrativo:

\begin{tabular}{|l|l|}
\hline $\begin{array}{l}\text { A Tartalira já espiava } \\
\text { o mundo de fora } \\
\text { com olhos de assombro. }\end{array}$ & $\begin{array}{l}\text { La Tortulira ya espiaba } \\
\text { el mundo ancho y ajeno } \\
\text { con ojos de asombro. } \\
\text { (KIRINUS, 1999, p.4-5, grifo } \\
\text { nosso). }\end{array}$ \\
\hline
\end{tabular}

Constatamos a substituição da expressão 'mundo de fora' pelas palavras 'mundo ancho y ajeno"7. Essa foi a maneira encontrada por Kirinus para aproximar, nas duas línguas, a principal característica da personagem: o mundo alheio à sua carapaça, era um tanto distante (ajeno) e amplo (ancho) para ela; um mundo que não se aproximava muito de suas vivências, enfim, o mundo de fora.

Observemos, também, a composição do nome da personagem, que é modificado durante a tradução. Isso acontece porque a autora o compôs fazendo uso de duas palavras: tartaruga e lira. Como a própria Kirinus afirma, Lira é o sobrenome da tartaruga, que permanece igual no português e no espanhol. No entanto, o princípio do nome sofre uma pequena alteração em função da maneira como o referido animal é nomeado nas duas línguas, em português, tartaruga, e em espanhol, tortuga.

Por outro lado, a proximidade existente entre o léxico das línguas, por vezes, permite que a autora consiga manter o mesmo efeito poético nos dois textos, e a ludicidade com as palavras. Isso acontece na página 14-16, onde a autora decompõe a palavra talento e provoca um efeito sonoro e rítmico condizente com a lentidão da personagem: "Era esse seu jeito./ e

\footnotetext{
${ }^{7}$ Atentamos para o fato de que tal expressão pode carregar um tom de intertextualidade com a obra El mundo es ancho y ajeno, novela do renomado escritor peruano Ciro Alegría. Publicada em 1941, a obra se destaca como uma das mais importantes
}

seu talento/ era lento/lento..." (KIRINUS, 1999, p.14). É como se a palavra talento deixasse um eco no rítmico com que desenvolvia suas atividades: lento, lento... O mesmo efeito é mantido no texto em espanhol: "Era así su estilo./ y su talento/ era lento, lento..." (KIRINUS, 1999, p.14).

Em contrapartida, na página 6 da obra Lâmpada de Lua/Lámpara de Luna, a brincadeira com a palavra não é permitida durante a inversão de idiomas. Trata-se do uso da palavra vaga-lume, que na produção é escrita sem hífen. No texto em português, a autora brinca com a composição do termo e quando faz referência ao suposto "desaparecimento" do 'vagalume', no momento em que a luz é acesa, ela diz: Vagalume / Va(ga) embora. É como se o eu lírico estivesse dando uma ordem para o inseto, mas fazendo uso da primeira parte de seu próprio nome: 'Va (ga)'. A forma utilizada, com a sílaba "ga" entre parêntesis, também pode ser associada ao sentido do verbo "vagar": desocupar um espaço em consequência da ação de ir embora.

A impossibilidade desse aspecto lúdico relativo à palavra vaga-lume ocorre porque, na língua espanhola, o inseto é denominado '/uciérnaga'. Nesse caso, a autora consegue sustentar apenas o sentido do texto - o ato de que, em decorrência do acendimento da luz, o inseto desaparece -, mas não a brincadeira proposta pela palavra na língua portuguesa:

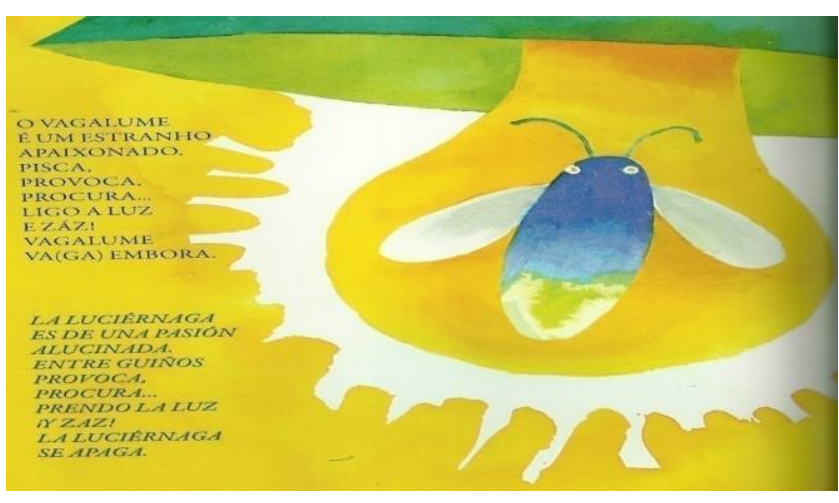

Figura 3: Brincadeira com a palavra vagalume Fonte: Lâmpada de Lua/ Lámpada de Luna, texto de Gloria Kirinus 
Por outro lado, na seguinte página, notamos a brincadeira de sentidos de uma expressão nos dois textos. A autora, mencionando a pressa cotidiana, escreve a expressão 'que sempre corre' como se fosse uma só palavra. O efeito de sentido pretendido é a rápida passagem do tempo cronológico 'quesemprecorre/quesiemprecorre' (KIRINUS, 2011, p.7) - e que é interrompida em decorrência do amor (ação simbolizada pelas reticências após a palavra tempo no último verso):

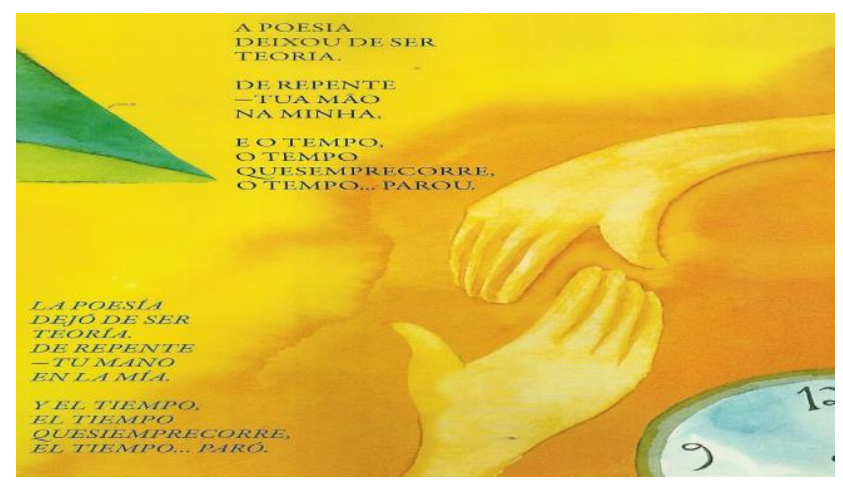

Figura 4: Expressão "quasesemprecorre"

Fonte: Lâmpada de Lua/ Lámpada de Luna, texto de Gloria Kirinus

Nesse processo de tradução, Kirinus também brinca com a disposição de seus textos nas páginas e consegue aproximar o sentido das palavras com as maneiras como são grafadas. Um exemplo disso está no uso da palavra "fio/hilo", localizada na página 14 do texto Se tivesse tempo/ Si tuviera tiempo. Graficamente, tanto em língua portuguesa como em língua espanhola, a palavra imita o formato de um fio, sendo disposta verticalmente, como se estivesse caindo do último verso do poema, já que a estrofe expõe as artimanhas de uma aranha, que sobe e desce pelo próprio fio:

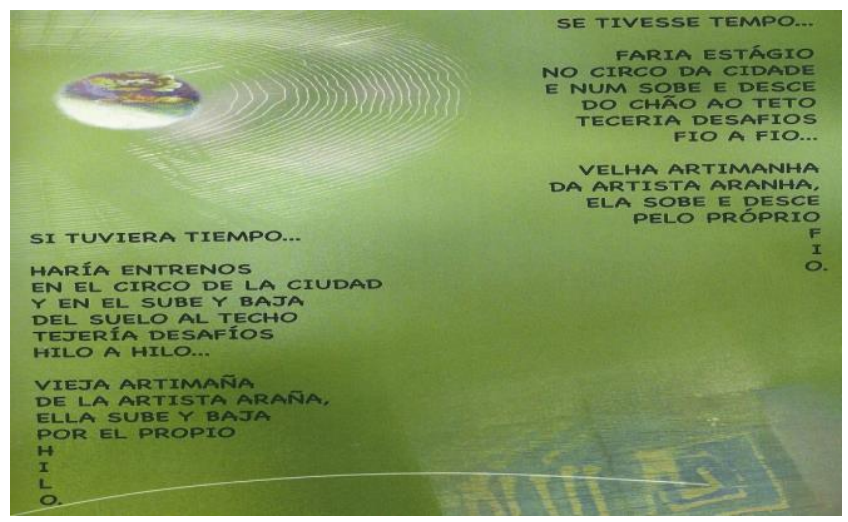

Figura 5: Disposição gráfica da palavra fio/hilo.

Fonte: Se tivesse tempo/Si tuviera tiempo, texto de Gloria Kirinus
Nosso exemplo final contempla outro sentido gráfico gerado pela distribuição do texto bilíngue de Kirinus. Ele acontece quando a autora se refere, em um de seus micropoemas, contido na referida obra, ao efeito visual gerado por um espelho. Nesse sentido, tenta reproduzi-lo através da escrita invertida do último verso, como se ele tivesse sido projetado em um espelho. Dessa maneira, Kirinus provoca a curiosidade do leitor, que terá a oportunidade de projetar a página do livro frente a um espelho e constatar que os demais versos do texto ficarão invertidos, ocasionando a facilidade para fazer a leitura do último verso, o qual, na projeção, ganhará o sentido correto:

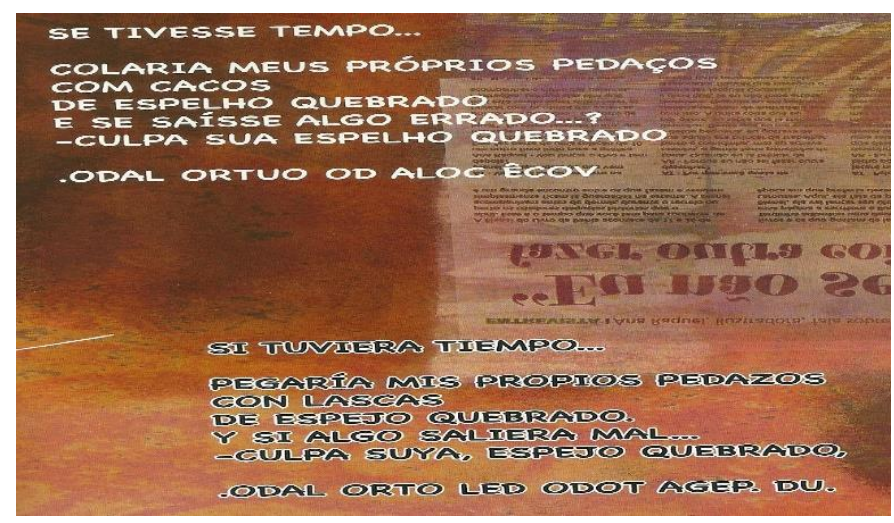

Figura 6: Efeito espelho. Gloria Kirinus.

Fonte: Se tivesse tempo/ Si tuviera tiempo, texto de

Essa coletânea de exemplos dá conta de um dos processos criativos da escrita de Kirinus: o texto bilíngue. Fazendo uso dos argumentos relativos ao processo de tradução, apresentamos alguns fatores que convertem Gloria Kirinus em autora-tradutora, na medida em que é fiel à sua produção primeira e, com exceção de poucos casos, consegue conservar a proposta lúdica de seu tratamento com as palavras.

\section{Para finalizar}

Ao escolher o português como língua literária, Gloria Kirinus consolida a sua obra a partir de um entrelaçamento de idiomas e de culturas. Usa, portanto, o bilinguismo como a principal ferramenta para a apresentação do multiculturalismo da América Latina.

As produções literárias com escrita dupla, português e espanhol, trazem, de forma implícita, a 
concepção da autora sobre a criança: protagonista, coautora dos textos, alguém que pode, inclusive, fazer opções: leio em português?; leio em espanhol?; considero os dois idiomas para a leitura?. Além disso, o leitor desses textos recebe um conteúdo rico em informações culturais e, por isso, é emancipado a partir de sua experiência leitora.

Kirinus, enquanto autora-tradutora, possivelmente, cria seus textos considerando a sua língua estrangeira, o português, e os traduz para a sua língua materna, o espanhol. Assim, age de forma poética, faz escolhas condizentes com as suas concepções de infância e de criança. Portanto, reduz o nível de assimetria, aspecto inevitável nas obras infantis, conseguindo produzir sentidos mais objetivos no processo de transição de um idioma para outro.

Por ser quem cria e traduz, o texto-base e o texto-segundo recebem a mesma atenção, têm o mesmo valor. Como conhecedora dos contextos, do público alvo, do gênero, da linguagem, não há infantilização no processo tradutório e o todo das obras é mantido. Obviamente, por ser um segundo texto, estruturado a partir de um outro idioma, algumas adaptações são inevitáveis, mas são notáveis o respeito e a fidelidade que Kirinus apresenta em relação ao original. As peculiares culturais, a ludicidade, a capacidade de entreter, de provocar prazer estético, ao mesmo tempo em que suscita aprendizagens, são itens conservados. Assim, as ilustrações, de extrema qualidade, repercutem um todo, sempre dispostas no centro das páginas, servindo de elo para os textos em português e em espanhol.

Na verdade, a literatura de Gloria Kirinus é um convite aos leitores de qualquer faixa etária. A identidade da América Latina, os seus idiomas, as expressões idiomáticas, os efeitos poéticos, os esquemas rítmicos, a disposição de palavras e de imagens caracterizam um povo que se reinventa a cada dia. Assim, temos em Kirinus um pouco do que é o constante traduzir-se do continente latino-americano.

\section{REFERÊNCIAS}

ALEXANDRE. Homenagem à Gloria Kirinus (texto publicado em 2010). Disponível em:

http://alexandremaisliteratura.blogspot.com.br/2010/11/homena gem-gloria-kirinus 6426.html. Acesso em: 22 jan. 2014

AMORIM, Alexandre. Tradução e versão: transferência, 2010.

Disponível em: Site:

http://www.educacaopublica.rj.gov.br/biblioteca/portugues/0028 html. Acesso em: 02 dez. 2014

BARROS, João de Deus Vieira (Org.). Imaginário e educação: pesquisas e reflexões. São Luis: EDUFMA, 2008.

GLORIA KIRINUS. Desenvolvido por Luciano. 2003-2014. Apresenta informações sobre a escritora Glória Kirinus. Disponível em: http://www.gloriakirinus.com.br/index.htm. Acesso em: 26 abr. 2020

KIRINUS, Gloria. Lâmpada de lua/Lámpara de Luna. llustrações de Rogério Borges. São Paulo: Larousse, 2011.

Quando as montanhas conversam/Cuando los cerros conversan. Ilustrações de Graça Lima. São Paulo: Paulinas, 2007.

Quando chove a cântaros/Cuando llueve a cántaros. Ilustrações de Graça Lima. São Paulo: Paulinas, 2012.

Se tivesse tempo/Si tuviera tiempo. llustrações de Ana

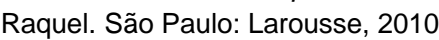

Sujeito leitor: Gloria Kirinus. Entrevistador: Cezar Tridapalli. Entrevista concedida ao site Midiaeducação; ago. 2011. Disponível em: http://midiaeducacao.com.br/?p=8414 Acesso em: 20 abr. 2014.

Tartalira/Tortulira. llustrações de Gê Orthof. São Paulo: Paulinas, 1999

Te conto que me contaram/Te cuento que me contaron. Ilustrações de Fernando Cardoso. São Paulo: Cortez, 2004.

MUNDT, Renata de Souza Dias. A adaptação na tradução de literatura infantojuvenil: necessidade ou manipulação? In: XI CONGRESSO INTERNACIONAL DA ASSOCIAÇÃO BRASILEIRA DE LITERATURA COMPARADA, TESSITURAS, INTERAÇÕES, CONVERGÊNCIAS. 2008. São Paulo. Anais (recurso eletrônico). São Paulo: ABRALIC, 2008. e-book. Disponível em:

http://www.abralic.org.br/anais/cong2008/AnaisOnline. Acesso em: 20 jun. 2014

PALAVRA FIANDEIRA. Entrevista com Gloria Kirinus. São Paulo. Ano 1. n. 5, dez. 2009. Disponível em: http://palavrafiandeira.blogspot.com.br/2009/12/palavrafiandeira-6.html. Acesso em: 20 abr. 2014.

RODRÍGUEZ, Alfredo Maceira. Aspectos comparativos entre o espanhol e o português (texto publicado em 2011). Disponível em: http://www.filologia.org.br/viisenefil/01.htm. Acesso em: 20 jun. 2014

SÓ PORTUGUÊS. Desenvolvido pelo grupo Virtuous. 20072014. Apresenta regras e curiosidades sobre a língua portuguesa. Disponível em: 
http://www.soportugues.com.br/secoes/morf/morf7.php. 20 jun.

2014.

VALÉRY, Paul. Primeira aula do curso de poética. In:

Variedades. São Paulo: lluminuras, 1999. p. 179-192.

VERDOLINI, Thais Helena Affonso. Tradução de literatura infantojuvenil contemporânea no Brasil. In: III CONGRESSO INTERNACIONAL DE LEITURA E LITERATURA INFANTIL E JUVENIL E II FÓRUM LATINO-AMERICANO DE

PESQUISADORES DE LEITURA. 2012. Porto Alegre. Anais (recurso eletrônico). Porto Alegre: PUCRS, 2012. Disponível em:

ebooks.pucrs.br/edipucrs/anais/IIICILLIJ/Trabalhos/.../thaisverdo

lini.pdf. Acesso em: 20 jun. 2014.

\section{COMO CITAR ESSE ARTIGO}

LOPES, Daiane. O traduzir-se de Kirinus: Textos bilíngues e literatura infantil. Signo, Santa Cruz do Sul, v. $46, \mathrm{n}$. 87, $\quad$ set. 2021. $\quad$ ISSN $1982-2014 . \quad$ Disponível em: <https://online.unisc.br/seer/index.php/signo/article/view/16734>.doi:https://doi.org/10.17058/signo.v46i87.1 6734. 